\title{
Opinion
}

\section{Three-dimensional power Doppler derived vascular indices: what are we measuring and how are we doing it?}

The role of Doppler in the assessment of fetal and placental blood flow is well-established ${ }^{1}$. However, as exemplified by the large variability of results published in the literature, its role in the evaluation of uterine and ovarian hemodynamics is not so clearly defined. Velocimetric indices such as pulsatility index and resistance index have been shown to provide useful information on uterine perfusion and angiogenesis in the ovarian follicle and certain cancers, but have not been adopted to any significant degree into clinical practice. Because of the advantages of power Doppler compared with conventional two-dimensional color Doppler ${ }^{2}$, some investigators have advocated its use for blood flow mapping ${ }^{3,4}$. However, this technique only provides information on the 'vascular map' of a given region of interest and assessment relies largely on the subjective impression of the examiner.

The advent of three-dimensional (3D) power Doppler ultrasound has begun a new era in tissue and organ vascularization research. Using this technique, we can now assess a virtually reconstructed vascular tree within a volume of interest ${ }^{5}$ and can 'objectively' determine its vascularization by calculating indices using the specially designed VOCAL ${ }^{\text {TM }}$ software (GE Medical Systems, Zipf, Austria $)^{6}$. Objective and non-invasive quantification of vascularization of a given tissue volume holds much promise, particularly because this method has proved to be highly reproducible between observers (thereby overcoming one of the main limitations of conventional Doppler ultrasound $)^{7-9}$.

Since the pioneering study of Pairleitner et al. ${ }^{6}$ in 1999 , more than 100 papers have been published analyzing the role of 3D power Doppler ultrasound in almost all areas of obstetrics and gynecology, including placental and fetal vascularization ${ }^{10,11}$, reproductive medicine ${ }^{12,13}$, gynecological endocrinology ${ }^{14}$, gynecological oncology ${ }^{15-17}$, breast pathology ${ }^{18}$ and the pelvic floor ${ }^{19}$.

Despite this abundance of literature on the application of 3D power Doppler ultrasound, it seems that so far few have stopped to ask what we are measuring. Calculation of the three 3D power Doppler ultrasound vascular indices, the vascularization index (VI), flow index (FI) and vascularization flow index (VFI), is based on and related to the total and relative amounts of power Doppler information within the volume of interest. VI denotes the ratio of color-coded voxels to all voxels within the volume and is expressed as a percentage, FI represents the mean power Doppler signal intensity from all color-coded voxels and VFI is the simple mathematical relationship derived from multiplying VI by FI and dividing the result by $100^{6}$. Both FI and VFI are unitless and are expressed as a numerical value ranging from 0 to 100 . The indices are thought to reflect the number of vessels within the volume of interest (VI), the intensity of flow at the time of the 3D sweep (FI), and both blood flow and vascularization $(\mathrm{VFI})^{6}$.

Although our knowledge about what these indices are actually measuring is limited, most examiners involved with the use of power Doppler are aware that several factors affect the power Doppler signal ${ }^{20,21}$. Yet, studies evaluating how machine settings affect measurements are scanty ${ }^{22}$. In this issue of the Journal, three papers make a significant contribution to the understanding of what these indices are measuring and how machine settings affect the measurements ${ }^{23-25}$. All three studies were performed in an in-vitro setting using a flow phantom experiment.

In the first study by Raine-Fenning $\mathrm{et} \mathrm{al}^{23}$, the authors evaluated the relationship of VI, FI and VFI values with vessel number, flow rate, attenuation and 'erythrocyte' density. They found a positive linear relationship between VI and VFI and all these factors except attenuation, which showed a negative relationship. In other words, with increasing number of vessels, volume flow or erythrocyte density, VI and VFI values increase. In the case of VI, these findings are particularly interesting. VI actually quantifies the number of color-coded voxels, which does not necessarily mean the number of vessels. However, in this phantom study, the authors found a correlation between the number of color-coded voxels and 'number of vessels'. This finding is in agreement with preliminary data from in-vivo studies that showed that VI correlates positively with microvessel density count as assessed by immunohistochemical techniques ${ }^{26}$. In contrast, the further the object under investigation is from the transducer, the lower the values obtained. This is of clinical relevance, because the route - transvaginal or transabdominal - should be taken into account when performing the calculations, as should the distance between the probe and the object under investigation. However, Raine-Fenning et al. found that FI showed a 'more complex cubic relationship that is not always logical'. This could indicate that FI is less predictable than VI and VFI. For example, they discovered that VI and VFI increase steadily with an increasing number of vessels, while FI reached a peak with three vessels and decreased 
thereafter. Additionally, as the authors themselves proved, a greater distance from the transducer to the furthest 'vessels' in the phantom decreased the signal intensity, leading to an overall decrease of the power Doppler signal.

In their second paper, Raine-Fenning et al. ${ }^{24}$ demonstrate that machine settings and speed of acquisition affect significantly all three 3D power Doppler ultrasound indices. These findings could be anticipated because it is well known that machine settings affect the power Doppler signal ${ }^{20,21}$. A potential weakness of their study is that it used an ultrasound machine from the old Voluson series, the Voluson 530, which did not have the power Doppler sensitivity of equipment in current use. However, in my opinion, this fact does not invalidate their results. In fact, in the third study, by Schulten-Wijman et al. ${ }^{25}$, the more modern Voluson 730 Expert was used and the principal study findings, that machine settings affect VI and FI calculation, were similar. An interesting additional finding is that 'measured VI' overestimated 'actual VI' even with different machine settings by up to 44 times! The concept of 'actual VI', as described by the authors in the paper, could be misleading but they are probably right. The VI is just a ratio between colored and total voxels and, since voxels are actually small cubes that occupy a predetermined volume, in my opinion, the VI is in fact the ratio between the volume of colored voxels and the volume of the total voxels. However, what I cannot understand is how they obtained those results because, assuming that all colored voxels within the tube are detected by the machine, the VI should be as high as the 'actual VI', but never higher. The experimental set-up in this study used a single tube, simulating one vessel, and it remains to be seen whether this finding could be extrapolated to true tissue vascularization where multiple vessels exist. Notwithstanding, this fact should be taken into consideration when measuring the VI in a single vessel, such as the uterine, umbilical, or fetal middle cerebral artery. Schulten-Wijman et al. also propose that the term 'flow index' be replaced by 'power index', a suggestion that I would endorse, because what we are actually measuring is mean power Doppler signal intensity.

Although it should be acknowledged that phantom studies for assessing Doppler systems have certain limitations ${ }^{27,28}$, and that the authors of these three studies used somewhat exaggerated machine settings that are not usually used in clinical practice, the results they report are relevant for at least two reasons. First, they provide evidence that machine settings affect VI, FI and VFI calculations. The primary consequence of this should be that all future papers published using this method should report the machine settings used and even the maximum depth of the objects evaluated when performing investigations. Furthermore, these results should prompt us to reach a consensus about which machine settings should be used, at least in the research situation, in order to allow meaningful comparison among studies. To the best of my knowledge, only the 3D Ultrasound Group from the Spanish Society of Ultrasound in Obstetrics and Gynecology has documented recommendations about machine settings to be used for research ${ }^{29}$ and, in my opinion, the International Society of Ultrasound in Obstetrics and Gynecology (ISUOG) should formulate a proposal for standardized settings to be used worldwide.

Second, these studies have shown how VI, FI and VFI indices are not related equally to the number of vessels and volume flow. This implies that the most appropriate index to use might be different depending on the clinical setting. For example, for analyzing tumor vascularization, VI may be preferred because in clinical practice oncologists and pathologists already use the mean vessel density (i.e. the number of vessels as a measure of tumor vascularization), the amount of flow being less relevant. However, when volume flow is the target of investigation, for example in maternal-fetal and reproductive medicine, it may be that FI is more useful.

I believe that we are a long way from clearly defining the role of $3 \mathrm{D}$ power Doppler ultrasound indices in clinical practice. However, steps such as those reported in this issue of the Journal are important for the scientific understanding of this technology.

\section{J. L. Alcázar \\ Department of Obstetrics and Gynecology, Clinica Universitaria de Navarra, School of Medicine, University of Navarra, Pamplona, Spain (e-mail:jlalcazar@unav.es)}

\section{REFERENCES}

1. Cetin I, Boito S, Radaelli T. Evaluation of fetal growth and fetal well-being. Semin Ultrasound CT MR 2008; 29: 136-146.

2. Bude RO, Rubin JM, Adler RS. Power versus conventional color Doppler sonography: comparison in the depiction of normal intrarenal vasculature. Radiology 1994; 192: 777-780.

3. Epstein E, Skoog L, Isberg PE, De Smet F, De Moor B, Olofsson PA, Gudmundsson S, Valentin L. An algorithm including results of gray-scale and power Doppler ultrasound examination to predict endometrial malignancy in women with postmenopausal bleeding. Ultrasound Obstet Gynecol 2002; 20: $370-376$.

4. Alcázar JL, Castillo G, Mínguez JA, Galán MJ. Endometrial blood flow mapping using transvaginal power Doppler sonography in women with postmenopausal bleeding and thickened endometrium. Ultrasound Obstet Gynecol 2003; 21: 583-588.

5. Zalud I, Shaha S. Evaluation of the utero-placental circulation by three-dimensional Doppler ultrasound in the second trimester of normal pregnancy. J Matern Fetal Neonatal Med 2007; 20: 299-305.

6. Pairleitner H, Steiner H, Hasenoehrl G, Staudach A. Threedimensional power Doppler sonography: imaging and quantifying blood flow and vascularization. Ultrasound Obstet Gynecol 1999; 14: 139-143.

7. Järvelä IY, Sladkevicius P, Tekay AH, Campbell S, Nargund G. Intraobserver and interobserver variability of ovarian volume, gray-scale and color flow indices obtained using transvaginal three-dimensional power Doppler ultrasonography. Ultrasound Obstet Gynecol 2003; 21: 277-282.

8. Raine-Fenning NJ, Campbell BK, Clewes JS, Kendall NR, Johnson IR. The reliability of virtual organ computer-aided analysis (VOCAL) for the semiquantification of ovarian, endometrial and subendometrial perfusion. Ultrasound Obstet Gynecol 2003; 22: 633-639. 
9. Alcázar JL, Mercé LT, Manero MG, Bau S, López-García G. Endometrial volume and vascularity measurements by transvaginal 3-dimensional ultrasonography and power Doppler angiography in stimulated and tumoral endometria: an interobserver reproducibility study. J Ultrasound Med 2005; 24: 1091-1098.

10. Rizzo G, Capponi A, Cavicchioni O, Vendola M, Arduini D. Placental vascularization measured by three-dimensional power Doppler ultrasound at 11 to $13+6$ weeks' gestation in normal and aneuploid fetuses. Ultrasound Obstet Gynecol 2007; 30: $259-262$.

11. Ruano R, Aubry MC, Barthe B, Mitanchez D, Dumez Y, Benachi A. Quantitative analysis of fetal pulmonary vasculature by 3-dimensional power Doppler ultrasonography in isolated congenital diaphragmatic hernia. Am J Obstet Gynecol 2006; 195: $1720-1728$.

12. Raine-Fenning NJ, Campbell BK, Kendall NR, Clewes JS, Johnson IR. Endometrial and subendometrial perfusions are impaired in women with unexplained subfertility. Hum Reprod 2004; 19: 2605-2614.

13. Mercé LT, Barco MJ, Bau S, Troyano J. Are endometrial parameters by three-dimensional ultrasound and power Doppler angiography related to in vitro fertilization/embryo transfer outcome? Fertil Steril 2008; 89: 111-117.

14. Järvelä IY, Mason HD, Sladkevicius P, Kelly S, Ojha K, Campbell S, Nargund G. Characterization of normal and polycystic ovaries using three-dimensional power Doppler ultrasonography. J Assist Reprod Genet 2002; 19: 582-590.

15. Alcázar JL, Mercé LT, García Manero M. Three-dimensional power Doppler vascular sampling: a new method for predicting ovarian cancer in vascularized complex adnexal masses. I Ultrasound Med 2005; 24: 689-696.

16. Mercé LT, Alcázar JL, López C, Iglesias E, Bau S, Alvarez de los Heros J, Bajo JM. Clinical usefulness of 3-dimensional sonography and power Doppler angiography for diagnosis of endometrial carcinoma. J Ultrasound Med 2007; 26: 1279-1287.

17. Kudla MJ, Timor-Tritsch IE, Hope JM, Monteagudo A, Popiolek D, Monda S, Lee CJ, Arslan AA. Spherical tissue sampling in 3-dimensional power Doppler angiography: a new approach for evaluation of ovarian tumors. J Ultrasound Med 2008; 27: 425-433.

18. Kuo SJ, Hsiao YH, Huang YL, Chen DR. Classification of benign and malignant breast tumors using neural networks and three-dimensional power Doppler ultrasound. Ultrasound Obstet Gynecol 2008; 32: 97-102.
19. Liang CC, Chang SD, Chang YL, Wei TY, Wu HM, Chao AS. Three-dimensional power Doppler measurement of perfusion of the periurethral tissue in incontinent women - a preliminary report. Acta Obstet Gynecol Scand 2006; 85: 608-613.

20. Gudmundsson S, Valentin L, Pirhonen J, Olofsson PA, Dubiel M, Marsal K. Factors affecting color Doppler energy ultrasound recordings in an in-vitro model. Ultrasound Med Biol 1998; 24: 899-902.

21. Yoon DY, Choi BI, Kim TK, Han JK, Yeon KM. Influence of instrument settings on flow signal and background noise in power Doppler US. An experimental study using a flow phantom with hyperechoic background. Invest Radiol 1999; 34: 781-784.

22. Dubiel M, Hammid A, Breborowicz A, Pietryga M, Sladkevicius P, Olofsson PA, Breborowicz GH, Gudmundsson S. Flow index evaluation of 3-D volume flow images: an in vivo and in vitro study. Ultrasound Med Biol 2006; 32: 665-671.

23. Raine-Fenning NJ, Nordin NM, Ramnarine KV, Campbell BK, Clewes JS, Perkins A, Johnson IR. Determining the relationship between three-dimensional power Doppler data and true blood flow characteristics: an in-vitro flow phantom experiment. Ultrasound Obstet Gynecol 2008; 32: 540-550.

24. Raine-Fenning NJ, Nordin NM, Ramnarine KV, Campbell BK, Clewes JS, Perkins A, Johnson IR. Evaluation of the effect of machine settings on quantitative three-dimensional power Doppler angiography: an in-vitro flow phantom experiment. Ultrasound Obstet Gynecol 2008; 32: 551-559.

25. Schulten-Wijman MJ, Struijk PC, Brezinka C, de Jong N, Steegers EA. Evaluation of volume vascularization index and flow index: a phantom study. Ultrasound Obstet Gynecol 2008; 32: $560-564$.

26. Park Y, Moon E, Park S, Roh J, Sangyoon P. Correlation between vascularization index (VI) and histologic tumor angiogenesis in cervical cancer: contrast enhanced threedimensional (3D) power Doppler vs. immunohistochemistry (IHC). Proc Am Soc Clin Oncol 2002; 21: 2529.

27. Enyakov AM. Metrological problems of testing medical ultrasonic equipment. Biomed Engin 2001; 35: 141-142.

28. Steinman AH, Tavakkoli J, Myers JG Jr, Cobbold RS, Johnston KW. Sources of error in maximum velocity estimation using linear phased-array Doppler systems with steady flow. Ultrasound Med Biol 2001; 27: 655-664.

29. Mercé LT (ed). Manual MISUS: Teoría y Práctica de la Ecografía y Angiografía Power Doppler Tridimensional en Obstetricia y Ginecología. Habe: Madrid, Spain, 2006. 